\title{
The Use of Monoclonal Antibodies in Treatment of Alzheimer Disease
}

\author{
Hemen Moradi-Sardareh ${ }^{1}$, Maryam Moradi ${ }^{2}$, Elham Bordbar ${ }^{3}$, Mohammadreza \\ Malekpour ${ }^{4}$, Sara Bagheri ${ }^{5}$, Nasrin Nakhodazadeh ${ }^{6}$, Shahin Rahbar ${ }^{7}$, Javad \\ Farhadian Asgarabadi ${ }^{8}$
}

${ }^{1}$ Department of Clinical Biochemistry, Medical School, Tehran University of Medical Sciences, Tehran, Iran. ${ }^{2}$ Department of Immunology and Hematology, Faculty of Medicine, Kurdistan University Of Medical Sciences, Sanandaj, Iran. ${ }^{3}$ Departments of Sciences, Faculty of Biochemistry, East Tehran Branch, Payame Noor University (PNU), Tehran, Iran. ${ }^{4}$ Department of Medical Nanotechnology, School of Advanced Technologies in Medicine, Tehran University of Medical Sciences, Tehran, Iran. ${ }^{5}$ Department of Clinical Biochemistry, Medical School, Hamadan University of Medical Sciences, Hamadan, Iran. ${ }^{6}$ In One of Laboratory Located on Southeast at Tehran Town. ${ }^{7}$ Institute of Medical History Studies, Islamic And Complementary Medicine, Iran University of Medical Sciences. ${ }^{8}$ Expert of Public Health, Shahroud University of Medical Sciences, Iran.

\begin{abstract}
Background and objective: Antibody molecules have similar structure but variable binding sites to antigen. Human antibodies are achieved by transgenic mouse technology or phage display. Antibodies are used for the treatment of different diseases. Alzheimer is a cow disease with a delayed onset overpresenting in adults in their 70 s to $90 \mathrm{~s}$. This disease is the leading cause of central nervous system (CNS) degeneration during 7 to 15 years in the aging population. Several hypotheses have offered monoclonal antibodies action mechanism in relation to amyloid cleaning at Alzheimer disease. According to this mechanism, the appropriate antibody passes blood-brain barrier, enters into brain, and binds to amyloid to launch its phagocytosis activity in microglia and/or macrophage/ monocytes infiltrating. The present study aimed to review antibody structure and the use of different antibodies for the treatment of Alzheimer disease.
\end{abstract}

Keywords: Alzheimer disease- antibody- Crenezumab- Solanezumab

Asian Pac J Cancer Biol, 1 (3), 59-66

\section{Introduction}

\section{Antibody structure}

Although antibody molecules have similar structure, they have different antigen-binding sites. Practical activities and normal chemical and physical features of antibodies are related to some antibodies regions which are called Fc regions (antigen does not usually connect to these regions and has low variety in antibody treasure). Each antibody molecule is consisted of two identical light and two identical heavy chains. Both heavy and light chains are composed of structural domains called immunoglobulin domains, having about 70-110 amino acids. Each chain is independently folded with a sphere-shaped pattern and Each domain is constructed from two $\beta$ sheets which are elements of protein structure made up of strands of the
Submission Date: 07/13/2016 Acceptance Date: 08/25/2016

polypeptide chain ( $\beta$ strands) packed together.

Heavy and light chains have variable regions in their $\mathrm{N}$-terminal, contributing to antigen recognition but include constant regions in their $\mathrm{C}$-terminal which play role in their practical activities. Each of variable or constant regions has only one domain immunoglobulin in light chains. Variable regions have different amino acid sequences in different antibody which are good indicators for produced antibodies diagnosis of different clones. Heavy chain variable region ( $\mathrm{VH})$ is placed in vicinity of the light chain variable region (VL) and forms the binding site to antigen together [1-3]. Antibody structure is presented in Figure 1.

1- Monoclonal antibody with murine origin is achieved through hybridomas technology. This antibody creates sensitive responses; it has a short half-life, and has poor

Corresponding Author:

Dr.Hemen Moradi-Sardareh

Department of Clinical Biochemistry, Medical School, Tehran University of Medical Sciences, Tehran, Iran.

Email: hemen.moradi@yahoo.com 
penetration into tumors $[4,5]$.

2- Chimeric antibodies which are determined by Xi

include Fab part of the mouse immunoglobulin and $\mathrm{Fc}$ part of a human immunoglobulin which is usually IgG, for example Rituximab [4-5].

3- Humanized antibodies are achieved by combination of highly variables regions of the mouse antibodies with human antibodies, $95 \%$ of which is humanized and it is determined by $\mathrm{Zu}$, for example Alemtuzumab. Humanized monoclonal antibodies are non-human species and their protein sequence is manipulated in order to increase their similarities with natural proteins produced by human body [4-5].

4- Human antibodies are achieved by transgenic mouse technology or phage display. Human immunoglobulin gene moves to the mouse genome and transgenic animal produced by injecting the intended antigen begins to produce antibody. To determine which antibody is used for each disease, a prefix is used before source determiner letter; for example, Vir or Vi are used for for viral disease, $\mathrm{Li}$ or Lim for vaccination, and $\mathrm{Tu}$ for cancer. Human complete monoclonal antibodies do not induce side effects associated with some humanized antibodies [4-5]. The types of therapeutic monoclonal antibody are shown in Figure 2.

\section{The use of monoclonal antibodies in treatment of different diseases}

The first monoclonal antibody was built in 1975 based on the works done by Kohler and Milestin [7]. A large numbers of monoclonal antibody have been accepted by FDA in various fields, including cancer (alemtuzumab, bevacizumab, ofatumumab, and rituximab), rheumatology (tocilizumab, adalimumab, and golimumab), gastro-intestinal diseases (nfliximab and certulizumabpegol), skin diseases (efalizumab and ustekinumab), and preventing organ rejection (daclizumab and basiliximab) [8].

\section{Alzheimer disease (AD)}

Alzheimer is a cow disease with a delayed onset overpresenting in adults in their 70 s to 90 s. This disease is the leading cause of central nervous system (CNS) degeneration during 7 to 15 years in the aging population. About 4 million Americans were intensively involved with $\mathrm{AD}$ and the amount of money that was directly spent on this disease was about 100 billion dollars in addition to financial burden imposed by indirect costs. It has been estimated that by a 5-year delay in the onset of Alzheimer saves about 50 billion dollars in the medical section [9].

Alois Alzheimer, a German psychiatrist and neuropathologist, introduced AD at 1906; the first symptoms observed by this scientist was pathological feature, including abnormal plaque of beta-amyloid protein (extracellular particle containing beta-amyloid) and neurofibrillar skeins (intracellular particle containing tau protein) in patient's brain pathology that was associated with verbal and behavioral disorders [10]. Since then, AD has become one of the most prevalent disorders in the elderly people so that it has allocated to itself the sixth leading cause of death and the fifth leading cause of death in people over 65 in America [10].

The inherited Alzheimer is associated with mutation in Amyloid Precursor Protein (APP) encoding gene [11]. which is located on chromosome 21 [12]. Mutation in presenilin-1 gene, which is an important gene in determining gamma secretase activity for beta amyloid production, can cause acceleration in early Alzheimer [13]. APO E4 gene locateding on chromosome 14 is indirectly related to $\mathrm{AD}$ [14]. Mutations lead to an early onset of $\mathrm{AD}$ as dominant autosomal.

Some hypotheses have been proposed for AD. To manage this disease, its mechanism should be clarified first.

\section{Tau protein}

Tau proteins are soluble proteins that are extensively present in neurons and play an important role in stabilizing microtubules, especially in axons of neurons [15]. The loss of microtubule binding capacity causes instability of the cellular skeleton, which ultimately causes the destruction and death of neurons [16]. Microtubule stabilizing drugs can be used as a strategy to treat $\mathrm{AD}$ [17]. In recent years, immunomodulation has been suggested as an acceptable option for removing Tau sediments [16].

\section{Cholinergic hypothesis}

AD Cholinergic hypothesis was dominant about 2 decades before. At AD, Acetyl choline is decreased in the cerebral cortex and hippocampus which can be due to sharp drop of acetyl choline transferase enzyme [18]. The brain's hippocampus, the main area involved in the processing of memory, is under the influence of cholinergic modulation [19]. One of the identified abnormalities is dependent on changes in neurotransmitter nerves, the destruction of cholinergic neurons, and the loss of cholinergic intakes to neocortex and hippocampus. Several studies have shown a reduction in nicotine and muscarinic receptors in the cortex and hippocampus of patients with AD [20].

\section{Dendrite hypothesis}

Dendritic abnormalities occur in the early stages of AD [21]. Amyloid-beta peptide $(A \beta)$ soluble oligomers are reported to be responsible for major dendritic pathologies that can trigger the activation of the $\mathrm{N}$-methyl- $\mathrm{D}$-aspartate (NMDAR) receptor by forming complexes with normal cell-surface prion protein (PrPC). The Prion proteins in neural synapses can interact with the Fyn tyrosine kinase-the metabotropic glutamate receptor complex. When $A \beta$ is attached to the MGluR5-Fyn-PrPC-complex, the Fyn kinase protein is activated and subsequently phosphorylates the tyrosine residue of NR2B subunit from the NMDAR and plays a significant role in advancing other signaling steps in the pathology of AD [22]. Two antibodies of Saracatinib and Masitinib are Fyn inhibitors, both of which are capable of blocking Fyn. Masitinib can also inhibit inflammation of the nerve tissue by inhibiting the SCF/c-Kit signaling on mast cells by blocking the interactions between microglia-activated mast cells [23]. 
Table 1. Naming Manner of Different Monoclonal Antibody

\begin{tabular}{|c|c|c|c|}
\hline Kind & Source & suffix & example \\
\hline & $\begin{array}{l}\text { an antibody that } \\
\text { completely derived from } \\
\text { mouse }\end{array}$ & -Omab & edrecolomab \\
\hline & $\begin{array}{l}\text { an antibody that contains } \\
\text { mouse binding site and } \\
\text { human Fc part }\end{array}$ & -ximab & Infliximab \\
\hline & $\begin{array}{l}\text { only include mouse CDR } \\
\text { regions }\end{array}$ & -zumab & daclizumab \\
\hline & $\begin{array}{l}\text { an antibody that } \\
\text { completely derived from } \\
\text { human source }\end{array}$ & -umab & adalimumab \\
\hline Hume & & & \\
\hline
\end{tabular}

Amyloid cascade hypothesis

This newer hypothesis about AD is based on disease pathological features. All Alzheimer patients, according to definition, have extracellular amyloid deposits that originally include $A \beta$.

Amyloid plaques have been considered as a vital stage in disease pathogenesis in genetic mutations studies [24]. Amyloid cascade hypothesis offers that peptide 42 production is increased of amyloid $\beta$ amino acids $(A \beta 42)$ or its decomposition reduction and also its accumulation leads to synaptic changes and $A \beta 42$ deposits at published plaques which this state is led to microglia and astrocytes activation. In active vaccination against $A \beta 42$, which patients with $\mathrm{AD}$ receive the antigen itself but in passive vaccination, peoples receive monoclonal antibodies against $A \beta 42$. Thereupon, neuronal homeostasis change, and oxidative damage lead to formation of such skeins that finally cause synaptic and neuronal function disorders and neurons selective loss $[25,26]$. This hypothesis has provided essential foundations for making new drugs.

The final reason for popularity of this hypothesis is that this intervention in cascade can prevent mental

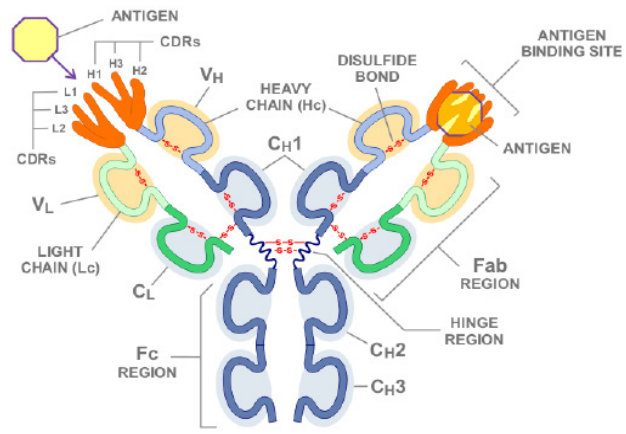

Figure 1. Antibody General Structure

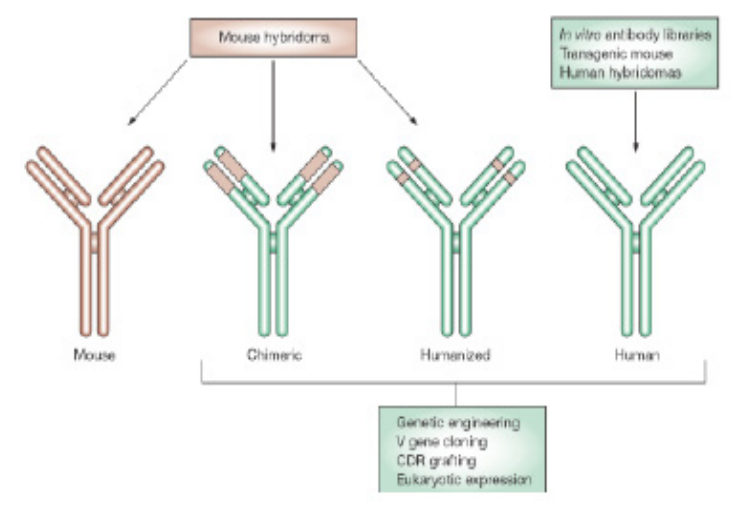

Figure 2. The Types of Therapeutic Monoclonal Antibody [4]. Mouse hybridomas technology produces mouse monoclonal antibody and genetic engineering has provided the ability to produce chimeric, human, and humanized monoclonal antibodies [6]. Mouse amino acid sequence and human sequences have been determined by brown and green colors, respectively. In comparison with chimeric monoclonal antibody, only CDR regions have mouse source in humanized monoclonal antibody. Antibodies variable domains are included 3 highly variable CDR that form antibody binding sites, therefore, it can be compared the antigen specificity with mouse appropriate CDRs bond in human variable regions (V) by genetic engineering methods [4].

destructionby genetic engineering methods[4].

and neuron loss. A $\beta$ peptide is a 40 to 42 amino acid piece which is created by a larger protein, APP. This peptide is produced by $2-\beta$ seretase ( $n$-terminal cutter) and $-\gamma$ secretase (C-terminal cutter) enzymes as APP productive slight product [25]. APP general structure is shown in Figure 3.

\section{3 forms of $A B$ will be free according to cut-off point by $\gamma$-secretase}

A: amino acid 38, B: amino acid 40, C: amino acid 42

A $\beta 42$ is more talented than AB40 peptide for aligomersation and amyloid fibrillar forms formation in which it is abundantly produced. A $\beta$ oligomers will apply their harmful effects through their direct connection to the neurons membrane or specific receptors needed for messaging [27-29].

APP is first broken by $\beta$-seretase which is an aspartyl protease (that is also called $\beta$-amyloid separator enzyme) in $\mathrm{A} \beta \mathrm{n}$-terminal domain and causes large actodomain pouring into extracellular fluid and duct and also leaves

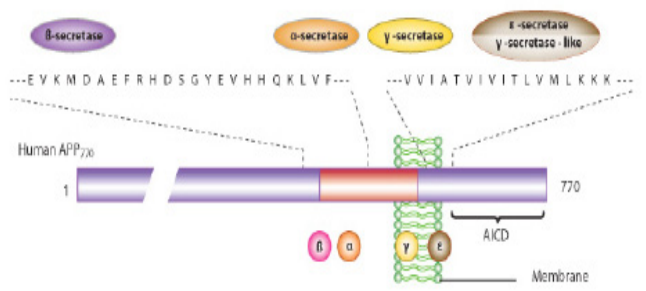

Figure 3. Amyloid Precursor Protein General Structure 


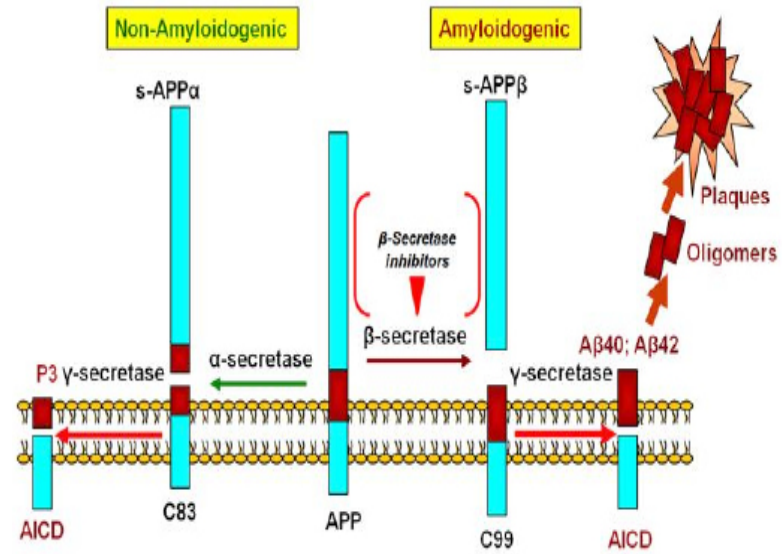

Figure 4. Shear Secretase Enzymes of Amyloid Precursor Protein. In effect of -a secretase enzyme an amino acid 83 piece will remain in membrane that is subsequently cut by $\gamma$-secretase; this direction cannot produce amyloid plaques. In next direction first amyloid precursor protein is cut by $\beta$-secretase and a 99 amino acid carboxyl terminal piece remains in membrane, then it is cut by -y secretase and produces 40 and 42 amyloid amino acid pieces that can form amyloid plaques.

Table 1. The Designed Monoclonal Antibodies for Alzheimer Disease

\begin{tabular}{|c|c|c|}
\hline Name & Kind & Epitope \\
\hline Bapineuzumab & humanized & N-terminal \\
\hline Solanezumab & humanized & $\begin{array}{c}\text { Central part (amino acids } \\
16 \text { to } 24 \text { ) }\end{array}$ \\
\hline Gantenerumab & human & $\begin{array}{c}\text { AB central part and } \\
\text { n-terminal }\end{array}$ \\
\hline Crenezumab & humanized & $\begin{array}{l}\text { Conformation epitope } \\
\text { including oligomeric } \\
\text { forms and AB proto- } \\
\text { fibrillar }\end{array}$ \\
\hline BAN2401 & Humanized & AB proto-fibrillars \\
\hline GSK 933776 & $\begin{array}{l}\text { humanized } \\
\text { IgG1 }\end{array}$ & N-terminal \\
\hline AAB-003 & $\begin{array}{l}\text { Fc-engineered } \\
\text { bapineuzumab }\end{array}$ & N-terminal \\
\hline SAR228810 & humanized & $\begin{array}{c}\text { Proto-fibrillars and ABs } \\
\text { with low molecular } \\
\text { weight }\end{array}$ \\
\hline $\begin{array}{l}\text { BIIB037/ } \\
\text { BART }\end{array}$ & Human & $\begin{array}{l}\text { insoluble fibrillar human } \\
\text { AB }\end{array}$ \\
\hline
\end{tabular}

a carboxyl terminal membrane piece that has 99 amino acids. This long piece will be subsequently broken by $\gamma$ - secretase and A $\beta$ is released [27-29]. Shear secretase enzymes of APP is shown in Figure 4.

The most APP shear production in A $\beta 16$ amino acid is created by -secretase $(90 \%)$ that prevents $A \beta$ peptide formation. The available documents suggest that carboxyl terminal shear by $\gamma$ - secretase can be created in amino acid $40 \mathrm{and} /$ or 42 . In natural conditions, $A \beta$ which is built in CNS has half-life clearing of 1-2 hours [25].
It has been offered that $A \beta$ accumulation in the extracellular space is responsible for neurons cytotoxic effects and it has been determined during the past decade that profibrillar forms and $\mathrm{A} \beta$ solution are also pathogen that can damage synapses and neurons.

\section{Therapeutic intervention strategies with A $\beta$ target}

There are 3 therapeutic intervention strategies with $\mathrm{A} \beta$ target right now, including the decreased $\mathrm{A} \beta$ production, $A \beta$ cleaning facilitates, and prevention of $\mathrm{A} \beta$ accumulation.

These strategies have been tested in clinical trials. Adjustment of $\gamma$ and $\beta$ secretase is important for decreased AB production, passive immunization by monoclonal antibody and active immunization to stimulate $A \beta$ cleaning, and finally preventing of $\mathrm{A} \beta$ accumulation with $\beta$-sheet shear enzymes and pathological chaperone inhibitors [30].

The designed monoclonal antibodies for AD treatment are from both humanized and human complete monoclonal antibody.

Several hypotheses have offered monoclonal antibodies action mechanism in relation to amyloid cleaning at AD [31]. The first offered mechanism is that the antibody bonding to amyloid leads to macrophage phagocytosis and complement activation [32]. Accordingly, it is assumed that the appropriate

antibody passes of blood-brain barrier, enters into brain, and binds to amyloid to launch this phagocytosis activity in microglia and/or macrophage/monocytes infiltrating. The second offered mechanism is called peripheral sink where the amyloid balance in the bloodbrain barrier is changed to its outside and leads to reduction of free $\mathrm{A} \beta$ concentration in blood.

A new approach for AD treatment by mabs is passive immunization against pyroglutamate- $3 \mathrm{~A} \beta$. Pyroglutamate $-3 \mathrm{~A} \beta$ resists against decomposition (it is neurotoxic) and may be act as $A \beta$ accumulation initiator. In preclinical trials, passive immunization with $A \beta$ monoclonal antibodies of pyroglutamate- 3 reduces plaque deposits [33-34].

Antibodies as the potential therapeutic agents in Alzheimer disease

The use of antibodies for Alzheimer disease treatment was initiated for the first time when antibodies raised against $A \beta$ peptide pieces in vitro for blocking amyloid fibrils formation of $A \beta$ [26]. Some specific functions of antibodies epitopes have been even determined and observed that antibodies against amino acids 1 to 28 were more effective for blocking fibrinogens while the antibodies against amino acids 8 to 17 were not influential [26].

Antibodies against peptide $n$-terminal parts are active (amino acids 1 to 16) while other antibodies against other parts are not effective (amino acids 13 to 28, amino acids 33 to 40) [35].

In 2001, it was showed that peripheral injection of anti-A $\beta$ monoclonal antibodies with high affinity led to remarkable increase of $A \beta$ in plasma and repetition of 
injections was associated with noticeable reduction of amyloid burden in vivo [36]. It was reported that only $25 \%$ of Alzheimer's disease patients treated with AN1792 had an anti-A $\beta$ antibody response and indicated that antibody responders scored significantly better in composite scores of memory functions than nonresponders or placebo-treated patients [37]. Anti-A $\beta$ antibodies can even solve pre-existing fibrils and prevent $A \beta$ fibrils neuronal toxicity [38].

Demattos et al [39] were unable in identifying and finding anti $A \beta$ antibodies in brain and argued that circulating antibodies acted as a pit or sink for $A \beta$ and changed $\mathrm{A} \beta$ balance between brain and blood toward its distribution in blood. These authors found that the initial speed that $A \beta$ accumulates in blood after anti $A \beta$ antibody injection was highly correlated withthe amount of amyloid burden in brain.

\section{Alzheimer's disease immunotherapy}

Different approaches have been proposed for the treatment of $\mathrm{AD}$, among which vaccination and immunotherapy are the most popular ones. Immunotherapy in AD includes 2 types of vaccinations: active vaccination against $A \beta 42$ in which patients receive antigens and inactive vaccinations, in which patients are given anti-A $\beta$ monoclonal antibodies [40].

\section{Anti-amyloid active immunotherapy}

It was reported in the mid 1990s that anti-A $\beta$ monoclonal antibodies can be used to prevent the formation of fiber $A \beta$ and decomposition of prefabricated fibers and plaques [26]. These antibodies decrease the levels of $A \beta$ in the brain and also improve memory performance [41]. Due to potentially dangerous autoimmune/inflammatory reactions from recently activated inflammatory $\mathrm{T}$ cells, new peptide vaccines have been designed in which the $\mathrm{T}$ cell activation sequences are eliminated and only fragments for the production of specific antibodies against $\mathrm{A} \beta$ remains. Three types of peptide vaccines for active immunization are CAD106, ACC001, and Affitope. The use of these vaccines reveals specific antibody reactions that have no symptoms of autoimmune inflammation. Various experiments have shown that CAD106 has favorable immune characteristics and adequate antibody response in $\mathrm{AD}$ patients. The ACImmune-35 vaccine (ACI-35) is designed to stimulate the production of antibodies that target tau protein in the brain [42-43].

\section{Inactive anti-amyloid immunotherapy}

Another approach is the use of human monoclonal antibodies, which are injected as inactive immunotherapy. Inactive anti-amyloid immunotherapy is an intravenous injection of anti-A $\beta$ monoclonal or polyclonal antibodies to the patient. In vivo studies have suggested that inactive immunization reduces the amount of brain amyloid. This can contribute to the neutralization of soluble amyloid oligomers that are increasingly precipitated and play an important role in the AD pathophysiology [16]. An overview of the used monoclonal antibodies for Alzheimer disease is shown in Table 1.

\section{Monoclonal antibodies Bapineuzumab}

Bapineuzumab is a humanized monoclonal antibody that acts against AB n-terminal [44]. Treatment with this monoclonal antibody reduces the amount of fibrillar amyloid burden in Alzheimer patients [45]. Bapineuzumab significantly reduces cerebral amyloid plaques and Tau phosphorylation in the cerebrospinal fluid [46].

\section{Solanezumab}

Solanezumab is a humanized monoclonal antibody that acts against central part of $\mathrm{AB}$ solution. This antibody prescription is highly tolerable; treatment with this antibody is correlated with dose-dependent increase in disconnected amyloid CSF (1-42), suggesting that its balance is changed from amyloid plaque form to amyloid (1-42) [47]. Solanezumab is used in AD patients and in elderly people who have normal memory thinking and function but may be at increased risk of $\mathrm{AD}$ in the future [46].

\section{Gantenerumab}

Gantenerumab is a human complete IgG1 monoclonal antibody that acts against both n-terminals and $\mathrm{AB}$ middle parts and is designed to bind to epitopes of beta-amyloid fibers with high affinity, which is used in individuals at high risk of developing advanced $\mathrm{AD}$ presenile due to genetic mutations [48]. Treatment of patients with mild to moderate Alzheimer by this antibody leads to significant decrease at $\mathrm{AB}$ levels in brain [47].

\section{Crenezumab}

Crenezumab is a humanized monoclonal antibody that acts against monomeric forms and conformation epitopes which includes oligomeric forms and $\mathrm{AB}$ proto-fibrillar [49-51].

\section{Solanezumab}

Solanezumab is an anti-A $\beta$ monoclonal antibody which has promoted Phase III clinical trials, directed against the $A \beta 13-28$ area and able to determine various $\mathrm{N}$-terminal truncated species such as A $\beta 3-42$ which are found in Alzheimer's disease senile plaques [52]. The recent failure of $\gamma$-secretase in inhibiting semagacestat, avagacestat, and monoclonal antibody bapineuzumab and the lack of highlighted beneficial impacts for solanezumab offer the re-examination of earlier intervention.

\section{Ponezumab}

Ponezumab is one of the other monoclonal anti-A $\beta$ antibodies targeting the amino acids 33-40 of the $A \beta$ peptide [40].

\section{MABT5102A}

MABT5102A is associated with $\mathrm{A} \beta$ monomers, Oligomers, and fibrils with high ratios [40].

\section{BAN2401}

BAN2401 is a humanized immunoglobulin G1 monoclonal antibody (IgG1) that is selectively bond to $\mathrm{AB}$ proto-fibrillars and causes the increase of the $\mathrm{A} \beta$ 
proto- fibrillars clearance and/or leads to neutralize toxic effects on neurons in the brain $[53,54]$.

\section{GSK933776}

GSK933776 is a humanized immunoglobulin G1 monoclonal antibody (IgG1) that acts against AB n-terminal. Its Fc domain has been mutated to reduce the risk of vasogenic edema [53].

\section{SAR 228810}

SAR228810 is a humanized monoclonal antibody that acts against proto-fibrillars and ABs with low molecular weight [53].

\section{BIIB037/BART}

BIIB037/BART is a human complete IgG1 monoclonal antibody that acts against insoluble fibrillar human AB [53].

\section{Immunotherapy against Tau}

Immunotherapy can also act as an approach to target Tau protein. In fact, it has been shown that the reduction of Tau sedimentation and the improvement of clearing of Tau oligomers and insoluble deposits can all be accomplished with immunotherapy [55].

In Conclusion, based on reports from previous studies infectious disorders and metabolic disorders, including diabetes and metabolic syndrome[56-60]and cancer had high rate of prevalence[61-63].For treatment of the large ranges of diseases, nanotechnology had noticeable role whichnanoparticles have some practices, in medicine and manufacturing [62-63].

Different nanotechnology based strategies such a nanoparticles have important role in drug delivery and therapy [64-66]. Indeed, the treatments for some prevalent disorders including cancer are chemotherapy and herbal based therapeutic agents [66-69]. In this regards monoclonal antibodies are involved in the field of large numbers of different disorders.

Designing monoclonal antibody is a new and appropriate approach for different diseases treatment in different fields. This monoclonal antibodies evolution will be promising in those diseases that there is not have not any specific and definitive treatment for them right now. Monoclonal antibodies have been designed against different kinds of $\mathrm{AB}$ that their purposes are cleaning toxic $\mathrm{ABs}$ from brain, amyloid cascade inhibition, and preventing of neuronal degeneration and brain function. The results are very promising in relation to multiple sclerosis disease, too. It is essential to mention that A slight percentage of antibodiespasses the blood brain barrier in normalsubjects $(<0.1 \%)$, with a somewhat higherpercentage in patients with $\mathrm{AD}(0.5-1.0 \%)$; thus, it may be beneficial to search ways toproduce new drug for AD.

\section{References}

1. C. A. Janeway Jr, P. Travers, M. Walport, and M. J. Shlomchik, "The structure of a typical antibody molecule," 2001.

2. K. Murphy and C. Weaver, Janeway's immunobiology. Garland Science, 2016.

3. K. D. Elgert, Immunology: understanding the immune system. John Wiley \& Sons, 2009.

4. R. Hohlfeld and H. Wekerle, "Drug insight: using monoclonal antibodies to treat multiple sclerosis," Nature Reviews. Neurology, vol. 1, no. 1, p. 34, 2005.

5. S. Swaminathan and S. Riminton, "Monoclonal antibody therapy for non-malignant disease," Issues, p. 1, 2006.

6. O. H. Brekke and I. Sandlie, "Therapeutic antibodies for human diseases at the dawn of the twenty-first century," Nature reviews. Drug discovery, vol. 2, no. 1, p. 52, 2003.

7. G. Köhler and C. Milstein, "Continuous cultures of fused cells secreting antibody of predefined specificity," Nature, vol. 256, no. 5517, pp. 495-497, 1975.

8. P. Rommer, A. Dudesek, O. Stüve, and U. Zettl, "Monoclonal antibodies in treatment of multiple sclerosis," Clinical \& Experimental Immunology, vol. 175, no. 3, pp. 373-384, 2014.

9. D. Morgan, "Antibody therapy for Alzheimer's disease," Expert review of vaccines, vol. 2, no. 1, pp. 53-59, 2003.

10. D. H. Small and R. Cappai, "Alois Alzheimer and Alzheimer's disease: a centennial perspective," Journal of neurochemistry, vol. 99, no. 3, pp. 708-710, 2006.

11. R. Mayeux, "Early Alzheimer's disease," New England Journal of Medicine, vol. 362, no. 23, pp. 2194-2201, 2010.

12. A. M. Coppus et al., "Plasma $\beta$ amyloid and the risk of Alzheimer's disease in Down syndrome," Neurobiology of aging, vol. 33, no. 9, pp. 1988-1994, 2012.

13. A. M. Issa et al., "The efficacy of omega- 3 fatty acids on cognitive function in aging and dementia: a systematic review," Dementia and geriatric cognitive disorders, vol. 21, no. 2, pp. 88-96, 2006.

14. Y. Liu, L. Yang, K. Conde-Knape, D. Beher, M. S. Shearman, and N. S. Shachter, "Fatty acids increase presenilin-1 levels and $\gamma$-secretase activity in PSwt-1 cells," Journal of lipid research, vol. 45, no. 12, pp. 2368-2376, 2004.

15. S. West and P. Bhugra, "Emerging drug targets for $A \beta$ and tau in Alzheimer's disease: a systematic review," British journal of clinical pharmacology, vol. 80, no. 2, pp. 221-234, 2015.

16. J. Folch López et al., "Current research therapeutic strategies for Alzheimer's disease treatment," Neural Plasticity, 2016, vol. 2016, p. 1-15, 2016.

17. L. Shefet-Carasso and I. Benhar, "Antibody-targeted drugs and drug resistance-challenges and solutions," Drug Resistance Updates, vol. 18, pp. 36-46, 2015.

18. P. J. Whitehouse, D. L. Price, A. W. Clark, J. T. Coyle, and M. R. DeLong, "Alzheimer disease: evidence for selective loss of cholinergic neurons in the nucleus basalis," Annals of neurology, vol. 10, no. 2, pp. 122-126, 1981.

19. K. Konishi et al., "Hypothesis of endogenous anticholinergic activity in Alzheimer's disease," Neurodegenerative Diseases, vol. 15, no. 3, pp. 149-156, 2015.

20. A. M Tata, L. Velluto, C. D'Angelo, and M. Reale, "Cholinergic system dysfunction and neurodegenerative diseases: cause or effect?," CNS \& Neurological DisordersDrug Targets (Formerly Current Drug Targets-CNS \& Neurological Disorders), vol. 13, no. 7, pp. 1294-1303, 2014.

21. J. N. Cochran, A. M. Hall, and E. D. Roberson, "The dendritic hypothesis for Alzheimer's disease pathophysiology," Brain research bulletin, vol. 103, pp. 18-28, 2014.

22. K. Yang, J. Belrose, C. H. Trepanier, G. Lei, M. F. Jackson, 
and J. F. MacDonald, "Fyn, a potential target for Alzheimer's disease," Journal of Alzheimer's Disease, vol. 27, no. 2, pp. 243-252, 2011.

23. F. Piette et al., "Masitinib as an adjunct therapy for mildto-moderate Alzheimer's disease: a randomised, placebocontrolled phase 2 trial," Alzheimer's research \& therapy, vol. 3, no. 2, p. 16, 2011.

24. J. Hardy and D. J. Selkoe, "The amyloid hypothesis of Alzheimer's disease: progress and problems on the road to therapeutics," science, vol. 297, no. 5580, pp. 353-356, 2002.

25 . M. J. Savage et al., "Turnover of amyloid $\beta$-protein in mouse brain and acute reduction of its level by phorbol ester," Journal of Neuroscience, vol. 18, no. 5, pp. 1743-1752, 1998.

26. B. Solomon, R. Koppel, E. Hanan, and T. Katzav, "Monoclonal antibodies inhibit in vitro fibrillar aggregation of the Alzheimer beta-amyloid peptide," Proceedings of the National Academy of Sciences, vol. 93, no. 1, pp. 452-455, 1996.

27. I. Benilova, E. Karran, and B. De Strooper, "The toxic A beta] oligomer and Alzheimer's disease: an emperor in need of clothes," Nature neuroscience, vol. 15, no. 3, pp. 349-357, 2012.

28. J. Schnabel, "Amyloid: little proteins, big clues," Nature, vol. 475, no. 7355, pp. S12-S14, 2011.

29. D. J. Selkoe, "Soluble oligomers of the amyloid $\beta$-protein impair synaptic plasticity and behavior," Behavioural brain research, vol. 192, no. 1, pp. 106-113, 2008.

30. T. Wisniewski and M. Sadowski, "Preventing $\beta$-amyloid fibrillization and deposition: $\beta$-sheet breakers and pathological chaperone inhibitors," BMC neuroscience, vol. 9, no. 2, p. S5, 2008.

31. D. Morgan, "Immunotherapy for Alzheimer's disease," Journal of internal medicine, vol. 269, no. 1, pp. 54-63, 2011.

32. F. Bard et al., "Peripherally administered antibodies against amyloid $\beta$-peptide enter the central nervous system and reduce pathology in a mouse model of Alzheimer disease," Nature medicine, vol. 6, no. 8, pp. 916-919, 2000.

33. J. L. Frost, B. Liu, M. Kleinschmidt, S. Schilling, H.U. Demuth, and C. A. Lemere, "Passive immunization against pyroglutamate- 3 amyloid- $\beta$ reduces plaque burden in Alzheimer-like transgenic mice: a pilot study," Neurodegenerative Diseases, vol. 10, no. 1-4, pp. 265-270, 2012.

34. V. Venkataramani, O. Wirths, H. Budka, W. Härtig, G. G. Kovacs, and T. A. Bayer, "Antibody 9D5 Recognizes Oligomeric Pyroglutamate Amyloid- $\beta$ in a Fraction of Amyloid- $\beta$ Deposits in Alzheimer's Disease without Cross-Reactivity with other Protein Aggregates," Journal of Alzheimer's Disease, vol. 29, no. 2, pp. 361-371, 2012.

35. B. Solomon, "Immunotherapeutic strategies for prevention and treatment of Alzheimer's disease," DNA and cell biology, vol. 20, no. 11, pp. 697-703, 2001.

36. R. B. DeMattos, K. R. Bales, D. J. Cummins, J.-C. Dodart, S. M. Paul, and D. M. Holtzman, "Peripheral anti-A $\beta$ antibody alters $\mathrm{CNS}$ and plasma $\mathrm{A} \beta$ clearance and decreases brain A $\beta$ burden in a mouse model of Alzheimer's disease," Proceedings of the National Academy of Sciences, vol. 98, no. 15, pp. 8850-8855, 2001.

37. S. Gilman et al., "Clinical effects of $A \beta$ immunization (AN1792) in patients with AD in an interrupted trial," Neurology, vol. 64, no. 9, pp. 1553-1562, 2005.

38. B. Solomon, R. Koppel, D. Frankel, and E. Hanan-Aharon, "Disaggregation of Alzheimer $\beta$-amyloid by site-directed $\mathrm{mAb}$," Proceedings of the National Academy of Sciences, vol. 94, no. 8, pp. 4109-4112, 1997.

39. R. B. DeMattos, K. R. Bales, D. J. Cummins, S. M. Paul, and D. M. Holtzman, "Brain to plasma amyloid- $\beta$ efflux: a measure of brain amyloid burden in a mouse model of Alzheimer's disease," science, vol. 295, no. 5563, pp. 2264-2267, 2002.

40. H. Jindal, B. Bhatt, S. Sk, and J. Singh Malik, "Alzheimer disease immunotherapeutics: then and now," Human vaccines \& immunotherapeutics, vol. 10, no. 9, pp. 27412743,2014

41. D. Schenk, R. Barbour, W. Dunn, and G. Gordon, "Immunization with amyloid-beta attenuates Alzheimerdisease-like pathology in the PDAPP mouse," Nature, vol. 400, no. 6740, p. 173, 1999.

42. D. Lambracht-Washington and R. N. Rosenberg, "Advances in the development of vaccines for Alzheimer's disease," Discovery medicine, vol. 15 , no. 84 , p. 319, 2013.

43. F. Panza, G. Logroscino, B. P. Imbimbo, and V. Solfrizzi, "Is there still any hope for amyloid-based immunotherapy for Alzheimer's disease?," Current opinion in psychiatry, vol. 27, no. 2, pp. 128-137, 2014.

44. S. Salloway et al., "A phase 2 multiple ascending dose trial of bapineuzumab in mild to moderate Alzheimer disease," Neurology, vol. 73, no. 24, pp. 2061-2070, 2009.

45. J. O. Rinne et al., "11 C-PiB PET assessment of change in fibrillar amyloid- $\beta$ load in patients with Alzheimer's disease treated with bapineuzumab: a phase 2, double-blind, placebo-controlled, ascending-dose study," The Lancet Neurology, vol. 9, no. 4, pp. 363-372, 2010.

46. H. O. Tayeb, E. D. Murray, B. H. Price, and F. I. Tarazi, "Bapineuzumab and solanezumab for Alzheimer's disease: is the 'amyloid cascade hypothesis' still alive?," Expert opinion on biological therapy, vol. 13, no. 7, pp. 1075-1084, 2013.

47. M. Farlow et al., "Safety and biomarker effects of solanezumab in patients with Alzheimer's disease," Alzheimer's \& Dementia, vol. 8, no. 4, pp. 261-271, 2012.

48. D. Novakovic et al., "Profile of gantenerumab and its potential in the treatment of Alzheimer's disease," Drug Design, Development and Therapy, vol. 7, p. 1359, 2013.

49. O. Adolfsson et al., "An effector-reduced anti- $\beta$-amyloid (A $\beta$ ) antibody with unique $a \beta$ binding properties promotes neuroprotection and glial engulfment of A $\beta$," Journal of Neuroscience, vol. 32, no. 28, pp. 9677-9689, 2012.

50. E. Callaway, “Alzheimer's drugs take a new tack," Nature, vol. 489, no. 7414, 2012

51. K. Garber, "Genentech's Alzheimer's antibody trial to study disease prevention," ed: Nature Research, 2012.

52. B. P. Imbimbo et al., "Solanezumab for the treatment of mildto-moderate Alzheimer's disease," Expert review of clinical immunology, vol. 8, no. 2, pp. 135-149, 2012.

53. N. D. Prins and P. Scheltens, "Treating Alzheimer's disease with monoclonal antibodies: current status and outlook for the future," Alzheimer's research \& therapy, vol. 5, no. 6, p. $56,2013$.

54. J. Moreth, C. Mavoungou, and K. Schindowski, "Passive anti-amyloid immunotherapy in Alzheimer's disease: What are the most promising targets?," Immunity \& ageing, vol. 10, no. 1, p. 18, 2013.

55. E. Kontsekova, N. Zilka, B. Kovacech, P. Novak, and M. Novak, "First-in-man tau vaccine targeting structural determinants essential for pathological tau-tau interaction reduces tau oligomerisation and neurofibrillary degeneration in an Alzheimer's disease model," Alzheimer's research \& therapy, vol. 6, no. 4, p. 44, 2014.

56. EbrahimiFar M, Mazdapour M, Kaki A, Mohammadi P, et al . Comparison of Biochemical Factors and Liver Enzymes in type 2 Diabetes Patients and Healthy Individuals. Bull EnvPharmacol Life Sci,2015. 4, 1-4. 
57.Goodarzi MT, Mohammadian M, BorzoueiSh,et al . Association between Plasma Cholesteryl Ester Transfer Protein activity and Lipid profiles in Metabolic Syndrome in an Iranian Population.Int Res J Biological Sci,2014..3;89-90.

58. Mohammadian M, ToofaniMilani A, Hassas M R,et al . Evaluation of Serum Iron, Zinc and Their Relationships with Glycemic Control Status in Iranian Elderly Women with Type 1 Diabetes Mellitus. Journal of Pharmacy and Pharmacology,2015. 3;411-416.

59. Rostamzadeh Z, Mohammadian M, Rostamzade A. Investigation of Pseudomonas aeruginosa Resistance Pattern against Antibiotics in Clinical Samples from Iranian Educational Hospital. Adv Microbiol;2016.6(3),190-194.

60. RostamzadehKhameneh Z, Mohammadian M, Nemati M, Rostamzade A. Investigation of Herpes Simplex Virus-2 (Hsv-2) Infection in Coronary Artery Disease Patients (CAD) in Population from Iran. Advances in Bioresearch.2015.6,74-78.

61. Mohammadi H, Abedi A, et al. Evaluation of synthesized platinum nanoparticles on the MCF-7 and HepG-2 cancer cell lines, International Nano Letters, 2013, vol. 3, no.1, p 1-5.

62. Khalili M, Akbarzadeh A, et al. The effect of nanoliposomal and PE gylated nanoliposomal forms of 6-gingerol on breast cancer cells, Research Journal of Recent Sciences, 2009, vol. 2277 , p. 2502.

63. Esfahani MKM et al. Pegylation of nanoliposomal paclitaxel enhances its efficacy in breast cancer, Tropical Journal of Pharmaceutical Research, 2014, vol. 13, no. 8, p. 1195-1198.

64. Izadi M, Ebrahimi Far M, Kanaani L, et al. Remove Nickel (II) From Drinking Water Using Thiol-Functionalized Chitosan. Advanced Biomedical Research, 2016. 7, 107-112.

65. Izadi M, EbrahimiShahemabadi H, Kanaani L, et al . Investigation of characteristics of loaded carboplatin on the liposomal nanoparticles on the cell carcinoma of the human brain c6. Adv. Biores,2016. 7, 113-118.

66. Poy D, Akbarzadeh A, EbrahimiShahmabadi H, et a. Reparation, Characterization and Cytotoxic Effects of LiposomalNanoparticles Containing Cisplatin: An in Vitro Study. Chemical Biology \& Drug Design,2016. 88, 568-573.

67. Amiri B, Ebrahimi Far M, Saffari Z, et al. Preparation, Characterization and Cytotoxicity of Silibinin Containing Nanoniosomes in T47D Human Breast Carcinoma Cells. Asian Pac J Cancer Prev, 2016.17, 3833-3836.

68. Rostaminasab S, Toofani Milani A, Mohammadian M, et al . Antitumor Immunostimulatory Effect of Sitosterol from Salvia atropatana on Tumor bearing mice. Adv Biores, 2015. 6, 133-40.

69. Sajjadiyan SZ, Toofani Milani A, Mohammadian M, et al. Preparation of silibinin loaded pegylatedniosomal nanoparticles and investigation of its effect on MCF-10A human breast cancer cell line. Der Pharm Lett, 2016. 8 , 70-5.

\section{(ब) 0 (}

This work is licensed under a Creative Commons AttributionNon Commercial 4.0 International License. 